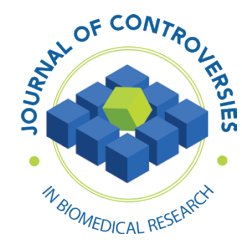

EDITORIAL

\title{
A Milestone for the Journal of Controversies in Biomedical Research
}

\section{Christudas Morais}

Journal of Controversies in Biomedical Research, Brisbane, Australia

\begin{abstract}
If every positive result published in peer-reviewed, biomedical journals were true, the world would be disease-free. On the contrary, the disease burden and the associated economic burden are on the rise. With unprecedented advances in technology, we have been able to manipulate genes and biological pathways and experimentally demonstrate that diseases can be cured by such approaches. We read these success stories in peer-reviewed journals. However, it is not an understatement that more than $95 \%$ of these experimental findings never translate to any useful clinical outcome. One of the reasons for this is that when one gene or biological pathway is manipulated, compensatory mechanisms come into play, causing or sustaining the same disease through alternate pathways or inducing adverse events that are worse than the disease itself. These results usually do not get published. Unless we choose to publish negative, null, and contradictory findings along with positive results, and challenge the existing paradigm, false science will flourish. The Journal of Controversies in Biomedical Research is a dedicated journal for the publication of negative, null, and controversial findings. The current issue of the journal contains a review article questioning the validity of the cholesterol-heart theory, which claims that high cholesterol levels lead to coronary artery obstruction and acute myocardial infarction and that lipid-lowering drugs would offer protection against such pathologies. I hope the journal and the article will stimulate intellectual scientific conversation and encourage researchers to publish their negative, null, and controversial research findings and views.
\end{abstract}

Keywords: biomedical research; cholesterol-heart theory; controversies; lipid-lowering drugs; negative results

Received: 20 October 2019; Accepted after revision: 25 October 2019; Published: 18 November 2019

Author for correspondence: Christudas Morais, Journal of Controversies in Biomedical Research, Brisbane, Australia. Email: editor@jcbmr.com

How to cite: Morais C. A Milestone for the Journal of Controversies in Biomedical Research. J Controversies Biomed Res. 2019;5(1):1-3

Doi: https://dx.doi.org/10.36255/jcbmr.2019.36

Copyright: The Author.

License: This open access article is licensed under Creative Commons Attribution 4.0 International (CC BY 4.0). http://creativecommons.org/ licenses/by/4.0

August 25, 2019 marked the fourth anniversary of the Journal of Controversies in Biomedical Research. The journal was launched with the purpose of publishing negative, null, and controversial research findings and views in an unbiased and nonjudgmental, yet scientifically plausible manner (1). Five days prior to the date of inception of the journal, on August 20, 2015, the Time magazine had published an article under the title "Modern science has a publish-or-perish problem," highlighting some of the irregularities tarnishing biomedical publishing (2). Since then, many journals have highlighted concerns regarding the growing lack of reproducibility and transparency in biomedical research. On October 18, 2018, the journal Nature released a special issue under the title "Challenges in irreproducible research" (3). The National
Institutes of Health has a website highlighting the problem of irreproducibility and the importance of research transparency and rigor (4). However, no pragmatic solution has been proposed by anyone.

As addressed in the first editorial of the journal (1), publishing negative, null, and controversial research findings and views is a pragmatic solution to address the reproducibility crisis and promote robust scientific research, integrity, and transparency. This editorial reflects on the major challenges of the past 4 years, introduces the review article of this issue that questions the cholesterol-heart theory, and looks forward to the future with optimism.

The major challenge is attracting submissions. The editorial of the inaugural issue identified many potential stumbling 
blocks in attracting submissions (1). After 4 years of analyzing the feedback of researchers, through private correspondence and conversations, the single factor that stands out is the inherent fear of discrimination - being viewed negatively by peers with potential detrimental effects on funding applications, future collaborations, and academic promotion. While this fear is justified, not publishing negative, null, and controversial findings is contrary to the three core principles of research: ethics, transparency, and scientific progress.

If our pioneers were afraid of discrimination and peer pressure, we would still believe the Earth is flat and that the Earth is the center of the solar system. Not many researchers know that Hans Krebs' paper on citric acid cycle (the Krebs' cycle), the very central driver of cellular respiration, was rejected by the journal Nature in 1937 (5). Hans Kreb subsequently was awarded the Nobel Prize in Medicine in 1953 for the discovery. The first paper describing polymerase chain reaction (PCR) by Kary B. Mullis was rejected by the journal Science (5). The Nobel Prize in Chemistry was awarded to Karry Mullis in 1993 for the invention. "Everyone was against me. But I knew I was right," were the words of the Australian gastroenterologist Dr. Barry Marshall, when he was ridiculed for suggesting that peptic ulcer was caused by bacteria and not by stress, spicy foods, or too much stomach acid (6). He went on to isolate the bacterium Helicobacter pylori from biopsy samples, drank a broth of $H$. pylori and developed the ulcer himself (7) to prove his point. Barry Marshall won the Nobel Prize for his discovery in 2005.

This is not to suggest that every rejected idea or paper will win the Nobel Prize, but to highlight the fact that if we choose to bury our negative, null, and controversial research findings or views, we will not only be failing our moral responsibility to society but also hindering scientific progress.

The current issue of the Journal of Controversies in Biomedical Research is released with a review article (8), questioning the validity of the traditional cholesterol-heart theory, which claims that high cholesterol levels lead to coronary artery obstruction and acute myocardial infarction and that cholesterol-lowering drugs would offer protection against coronary artery obstruction, myocardial infarctions, or any of the cholesterol-mediated cardiovascular complications. This is a controversial area, often questioning the efficacy of statins in reducing myocardial complications, despite their undisputed effect on lowering low-density lipoproteins. In the current review, the authors, Mikael Rabaeus and Michel de Lorgeril, rationalize that if cholesterol-lowering drugs other than statins reduce the risk of cardiovascular complications, it would confirm that the cholesterol-heart theory is correct. However, if these compounds fail to reduce risk, the cholesterol-heart theory should be rejected.

Accordingly, the authors review seven randomized clinical trials testing the efficacy of cholesteryl ester transfer protein
(CETP) and proprotein convertase subtilisin/kexin type 9 (PCSK9) serine protease inhibitors that are demonstrated to inhibit low-density lipoproteins (the so-called bad cholesterol) and increase the high-density lipoprotein (the so-called good cholesterol). After systematically analyzing the results, the authors show that despite these studies demonstrating significant decrease in low-density lipoproteins and an increase in high-density lipoproteins, no clinically significant benefits in terms of reducing or preventing cardiovascular complications were observed in the majority of patients. Thus, the authors conclude that the cholesterol-heart theory should be seriously challenged.

Some researchers may agree with the authors' conclusion, and others may disagree. The journal offers an opportunity for both sides to be heard. Those who agree with the authors' conclusion and feel that the cholesterol-heart theory should be challenged can submit additional evidence. Those who disagree are also invited to submit wellthought-out, well-referenced criticism of the contents of the article itself, avoiding criticism of a personal nature of the authors, editors, or publisher. Very importantly, in line with the policy of the journal, complete declaration of conflicts of interest is necessary. It appears clear that only an unbiased scientific discussion can contribute to the truth about the cholesterol-heart theory.

The Journal of Controversies in Biomedical Research continues to publish articles for free and provides unrestricted open access to its contents as a service to the scientific community. For long-term sustainability, some form of author fee may be implemented in the future. Should a fee be implemented, such information will be publicly available on the journal's site. Currently, the journal does not rely on author fees and has sufficient resources for sustainability.

I take this opportunity to thank the former editor-in-chief, Dr. Louis Vitetta, for his support over the past 4 years. I conclude this editorial with the hope that my fellow researchers will consider publishing their negative, null, and controversial research findings and views in the journal.

\section{Conflict of interest}

$\mathrm{CM}$ is the founder and editor-in-chief of the Journal of Controversies and Biomedical Research. This editorial was peer reviewed by independent reviewers.

\section{References}

1. Morais C, Vitetta L. Journal of Controversies in Biomedical Research - The need of the hour. J Controversies Biomed Res. 2015;1(1):1-3.

2. Kluger J. Modern science has a publish-or-perish problem [Internet]. [cited 2019 Oct 9]. Available from: https://time. com/4004391/modern-science-has-a-publish-or-perish-problem/

3. Challenges in irreproducible research. Available from: https:// www.nature.com/collections/prbfkwmwvz 
4. National Institutes of Health. Rigor and reproducibility [Internet]. [cited 2019 Oct 9]. Available from: https://www.nih. gov/research-training/rigor-reproducibility

5. Macdonald F. 8 scientific papers that were rejected before going on to win a Nobel Prize [Internet]. [cited 2019 Oct 14]. Available from: https:/www.sciencealert.com/these-8-papers-were-rejected-before-going-on-to-win-the-nobel-prize

6. Beattie-Moss M. Gut instincts: A profile of Nobel laureate Barry Marshall [Internet]. [cited 2019 Oct 14]. Available from: https://news.psu.edu/story/140921/2008/02/04/research/ gut-instincts-profile-nobel-laureate-barry-marshall

7. Weintraub, P. The doctor who drank infectious broth, gave himself an ulcer, and solved a medical mystery [Internet]. [cited 2019 Oct 14]. Available from. http://discovermagazine.com/2010/ mar/07-dr-drank-broth-gave-ulcer-solved-medical-mystery

8. Rabaeus M, de Lorgeril M. A systematic review of trials testing CETP and PCSK9 inhibitors - The cholesterol-heart theory: Time for a requiem? J Controversies Biomed Res. 2019;5(1):4-11. 